\title{
Closed-Loop Control of Mechanical Ventilation: Description and Classification of Targeting Schemes
}

\author{
Robert L Chatburn MHHS RRT-NPS FAARC and Eduardo Mireles-Cabodevila MD
}

\author{
Introduction \\ A Taxonomy of Closed-Loop Control \\ Control Theory \\ Targeting Schemes \\ Manual Targeting Schemes \\ Set-Point Targeting \\ Dual Targeting \\ Servo Targeting Schemes \\ Automatic Tube Compensation \\ Neurally Adjusted Ventilatory Assist \\ Proportional Assist Ventilation \\ Automatic Targeting Schemes \\ Adaptive Targeting \\ Optimal Targeting \\ Intelligent Targeting Schemes \\ SmartCare/PS \\ Caveats \\ Summary
}

There has been a dramatic increase in the number and complexity of new ventilation modes over the last 30 years. The impetus for this has been the desire to improve the safety, efficiency, and synchrony of ventilator-patient interaction. Unfortunately, the proliferation of names for ventilation modes has made understanding mode capabilities problematic. New modes are generally based on increasingly sophisticated closed-loop control systems or targeting schemes. We describe the 6 basic targeting schemes used in commercially available ventilators today: set-point, dual, servo, adaptive, optimal, and intelligent. These control systems are designed to serve the 3 primary goals of mechanical ventilation: safety, comfort, and liberation. The basic operations of these schemes may be understood by clinicians without any engineering background, and they provide the basis for understanding the wide variety of ventilation modes and their relative advantages for improving patient-ventilator synchrony. Conversely, their descriptions may provide engineers with a means to better communicate to end users. Key words: taxonomy; targeting schemes; ventilation modes. [Respir Care 2011;56(1):85-98. (c) 2011 Daedalus Enterprises]

\footnotetext{
Robert L Chatburn MHHS RRT-NPS FAARC is affiliated with the Respiratory Institute, The Cleveland Clinic, and with Lerner College of Medicine, Case Western Reserve University, Cleveland, Ohio. Eduardo Mireles-Cabodevila MD is affiliated with the Division of Pulmonary and Critical Care Medicine, Department of Medicine, University of Arkansas for Medical Sciences, Little Rock, Arkansas.
}

Mr Chatburn has disclosed relationships with IngMar, Hamilton, Covidien, Dräger, CareFusion, Newport, IngMar, Radiometer America, Breathe

\footnotetext{
Technologies, and the Alpha-1 Antitrypsin Foundation. Dr MirelesCabodevila has disclosed no conflicts of interest.

Mr Chatburn presented a version of this paper at the 46th RESPIRATORY CARE Journal Conference, "Patient-Ventilator Interaction," held March 1921, 2010, in Cancún, Quintana Roo, Mexico.

Correspondence: Robert L Chatburn MHHS RRT-NPS FAARC, Respiratory Therapy, M-56, The Cleveland Clinic, 9500 Euclid Avenue, Cleveland OH 44195. E-mail: chatbur@ccf.org.
} 


\section{Introduction}

Over the last 10 years there have been more than a dozen good reviews of closed-loop control of mechanical ventilators and the various modes they have generated. ${ }^{1-17}$ Without exception, those authors took the approach of "name and describe," using the mode names coined by manufacturers and the descriptions from the operator's manuals. That approach is appropriate for the reader with a casual, general interest in modes or the need to know the details of a single mode. It is, perhaps, a less useful approach for those who need a broader understanding: the clinician who needs to master several ventilator platforms, the vendor's representative who must be conversant with both her own products and those of competitors, and, perhaps most important of all, the educator who must be able to compare and contrast all modes in a systematic, practical fashion. To serve these needs, we will attempt to take the discussion of this topic to the next level: that is, to classify closed-loop control schemes so that we may better understand their similarities, differences, and relative advantages. In so doing we hope to bridge the knowledge-gap between engineers and clinicians and promote communication between the 2 groups. In the process we will establish some fundamental concepts for a larger taxonomy of modes, and we present and discuss some representative control-system diagrams. A complete taxonomy of modes (though beyond the scope of this paper) will serve major stakeholders, including clinicians (who wish to improve patient care), educators (who need a basis for teaching systems), and vendors (to facilitate communications among clinicians, engineers, and marketers).

The fundamental problem facing these stakeholders is that there are apparently too many modes and too little evidence that may be used to compare them. We say "apparently" because, despite the fact that the 8th edition of Mosby's Respiratory Care Equipment ${ }^{18}$ lists 56 unique mode names, only about 2 dozen of them are actually unique modes when described at a level of detail that includes the targeting scheme (ie, the feedback control system the ventilator uses to deliver a specific ventilatory pattern, see Table 1). Furthermore, these modes can be identified using only 6 basic targeting schemes. When viewed from this perspective, the large number of ventilation mode names does not seem so intimidating.

\section{A Taxonomy of Closed-Loop Control}

\section{Control Theory}

The term "closed-loop control" refers to the use of a feedback signal to adjust the output of a system. Ventila-
Table 1. Ventilator Manufacturers' Ventilation Mode Names*

\begin{tabular}{|c|c|c|}
\hline Manufacturer & $\begin{array}{l}\text { Example } \\
\text { Ventilator }\end{array}$ & Manufacturer's Mode Name \\
\hline CareFusion & Avea & $\begin{array}{l}\text { Synchronized Intermittent } \\
\text { Mandatory Ventilation With } \\
\text { Machine Volume }\end{array}$ \\
\hline CareFusion & Avea & $\begin{array}{l}\text { Volume Control Assist Control } \\
\text { With Machine Volume }\end{array}$ \\
\hline Covidien & $\begin{array}{l}\text { Puritan Bennett } \\
\quad 840\end{array}$ & $\begin{array}{l}\text { Proportional Assist Ventilation } \\
\text { Plus }\end{array}$ \\
\hline Covidien & $\begin{array}{l}\text { Puritan Bennett } \\
\quad 840\end{array}$ & $\begin{array}{l}\text { Volume Control Ventilation } \\
\text { Assist/Control }\end{array}$ \\
\hline Dräger & Evita XL & Automatic Tube Compensation \\
\hline Dräger & Evita XL & $\begin{array}{l}\text { Intermittent Positive Pressure } \\
\text { Ventilation With Pressure } \\
\text { Limited Ventilation }\end{array}$ \\
\hline Dräger & Evita XL & $\begin{array}{l}\text { Mandatory Minute Volume } \\
\text { Ventilation }\end{array}$ \\
\hline Dräger & Evita XL & Proportional Pressure Support \\
\hline Dräger & Evita XL & SmartCare/PS \\
\hline Dräger & Evita XL & $\begin{array}{l}\text { Synchronized Intermittent } \\
\text { Mandatory Ventilation With } \\
\text { Pressure Limited Ventilation }\end{array}$ \\
\hline Hamilton & G5 & Adaptive Support Ventilation \\
\hline Maquet & Servo-i & AutoMode (PRVC - VS) \\
\hline Maquet & Servo-i & $\begin{array}{l}\text { Neurally Adjusted Ventilatory } \\
\text { Assist }\end{array}$ \\
\hline Maquet & Servo-i & Pressure Control \\
\hline Maquet & Servo-i & $\begin{array}{l}\text { Pressure Regulated Volume } \\
\text { Control }\end{array}$ \\
\hline Maquet & Servo-i & Volume Control \\
\hline Maquet & Servo-i & Volume Support \\
\hline Newport & e500 & $\begin{array}{l}\text { Synchronized Intermittent } \\
\text { Mandatory Ventilation }\end{array}$ \\
\hline Phillips & V200 & Pressure Support Ventilation \\
\hline Phillips & V200 & Spontaneous/Timed Ventilation \\
\hline Taema & Horus & Mandatory Rate Ventilation \\
\hline VersaMed & iVent201 & $\begin{array}{l}\text { Assist/Control (Adaptive Flow } \\
\text { and I-Time) }\end{array}$ \\
\hline VersaMed & iVent201 & $\begin{array}{l}\text { Pressure Controlled } \\
\text { Synchronized Mandatory } \\
\text { Ventilation }\end{array}$ \\
\hline VersaMed & iVent201 & $\begin{array}{l}\text { Volume Controlled } \\
\text { Synchronized Mandatory } \\
\text { Ventilation (Adaptive Flow } \\
\text { and I-Time) }\end{array}$ \\
\hline
\end{tabular}

* The numerous manufacturers' closed-loop ventilation mode names can be narrowed down to this list of representatives of the major control schemes. Each ventilator has more modes than are listed, but, for simplicity, only the unique modes are shown.

tors use closed-loop control to maintain consistent pressure and flow waveforms in the face of changing patient/ system conditions. ${ }^{19,20}$ This is accomplished by using the 


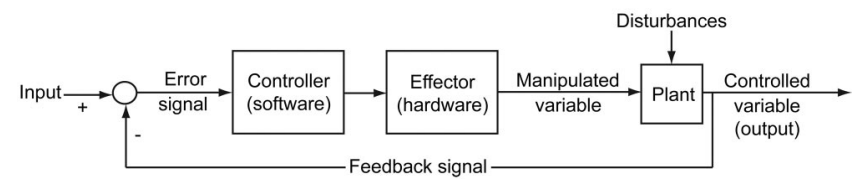

Fig. 1. Generalized control circuit (see text for explanation). The "plant" in a control circuit for mechanical ventilation is the patient.

output as a feedback signal that is compared to the operator-set input. The difference between the two is used to drive the system toward the desired output. For example, pressure-control modes use airway pressure as the feedback signal to control gas flow from the ventilator. Figure 1 shows a schematic drawing of a general control system. The input is a reference value (eg, operator preset inspiratory pressure) that is compared to the actual output value (eg, instantaneous value of airway pressure). The difference between those 2 values is the error signal. The error signal is passed to the controller (eg, the software control algorithm). The controller converts the error signal into a signal that can drive the effector (eg, the hardware) to cause a change in the manipulated variable (eg, inspiratory flow). The relationship between the input and the output of the controller is called the transfer function in control theory. ${ }^{21}$

Engineers need to understand the transfer function in terms of complex mathematical equations. Clinicians, however, need only understand the general operation of the function in terms of how the mode affects the patient's ventilatory pattern, and we will use that frame of reference in defining targeting schemes. The "plant" in Figure 1 refers to the process under control. In our case, the plant is the patient and the delivery circuit connecting the patient to the ventilator. The plant is the source of the "noise" that causes problems with patient-ventilator synchrony. At one extreme, a paralyzed patient and an intact delivery circuit pose little challenge for a modern ventilator to deliver a predetermined ventilatory pattern, and thus synchrony is not an issue. On the other extreme is a patient with an intense, erratic respiratory drive and a delivery circuit with leaks (eg, around an uncuffed endotracheal tube) making patient-ventilator synchrony virtually impossible. The challenge for both clinicians and engineers is to develop technology and procedures for dealing with this wide range of circumstances.

The plant alters the manipulated variable to generate the feedback signal of interest as the control (output) variable. Continuing with the example above, the manipulated variable is flow, but the feedback control variable is pressure (ie, ventilator flow times plant impedance equals airway pressure), as in pressure-control modes. Closed-loop control can also refer to the use of feedback signals to control the overall pattern of ventilation, beyond a single breath, such as the use of end-tidal carbon dioxide tension as a feedback signal to control minute ventilation. ${ }^{22}$

\section{Targeting Schemes}

The process of "setting" or adjusting a ventilation mode can be thought of as presetting various target values, such as tidal volume, inspiratory flow, inspiratory pressure, inspiratory time, frequency, PEEP, oxygen concentration, etc. We use the term "target" for 2 reasons. First, just like in archery, a target is aimed at but not necessarily hit, depending on the precision of the control system. An example would be setting a target value for tidal volume and allowing the ventilator to adjust the inspiratory pressure over several breaths to finally deliver the desired value. Indeed, in this case we could more accurately talk about delivering an average target tidal volume over time.

The second reason for using "target" is because the term "control" is over-used and we need it to preserve some conventional notions about modes such as "volume control" versus "pressure control." From this use of the term target, we can logically refer to the control system transfer function (relationship between the input and the output of the controller) as a targeting scheme. Tehrani has provided a fascinating history of ventilator targeting schemes, both commercial and experimental. ${ }^{23,24}$ The history of these systems clearly shows an evolutionary trend toward increasing levels of automation. In fact, as a first pass at sorting out the commercially available modes listed in Table 1, we can identify 3 groups of targeting schemes based on increasing levels of autonomy: manual, servo, and automatic (Table 2). Manual targeting schemes require the operator to adjust all the target values. Servo targeting schemes are unique in that there are no static target values; rather, the operator sets the parameters of a mathematical model that drives the ventilator's output to follow a dynamic signal (like power steering on an automobile). Automatic targeting schemes allow the ventilator to set some or all of the ventilatory targets, using either mathematical models of physiologic processes or artificial-intelligence algorithms.

\section{Manual Targeting Schemes}

Manual targeting schemes are those in which the operator directly adjusts the controller output. The adjustments may determine the entire output as a function of time (eg, presetting the inspiratory flow waveform [eg, rectangular, sinusoidal, or descending ramp]), peak flow, and inspiratory time. Alternatively, one might preset only a portion of the output, such as peak inspiratory pressure and inspiratory pressure rise time, with inspiratory time being unspecified. Or perhaps only one parameter of the output (eg, peak inspiratory pressure) might be adjustable, and the rest 
Table 2. Modes From Table 1 Sorted by Level of Autonomy

\begin{tabular}{|c|c|}
\hline Manufacturer's Mode Name & Autonomy \\
\hline Volume Control Ventilation Assist/Control & Manual \\
\hline Pressure Control & Manual \\
\hline $\begin{array}{l}\text { Synchronized Intermittent Mandatory } \\
\text { Ventilation }\end{array}$ & Manual \\
\hline $\begin{array}{l}\text { Pressure Controlled Synchronized Mandatory } \\
\text { Ventilation }\end{array}$ & Manual \\
\hline Spontaneous/Timed Ventilation & Manual \\
\hline Pressure Support Ventilation & Manual \\
\hline $\begin{array}{l}\text { Intermittent Positive Pressure Ventilation With } \\
\text { Pressure Limited Ventilation }\end{array}$ & Manual \\
\hline Volume Control & Manual \\
\hline $\begin{array}{l}\text { Volume Control Assist Control With Machine } \\
\text { Volume }\end{array}$ & Manual \\
\hline $\begin{array}{l}\text { Synchronized Intermittent Mandatory } \\
\text { Ventilation With Pressure Limited Ventilation }\end{array}$ & Manual \\
\hline $\begin{array}{l}\text { Synchronized Intermittent Mandatory } \\
\text { Ventilation With Machine Volume }\end{array}$ & Manual \\
\hline Automatic Tube Compensation & Servo \\
\hline Proportional Assist Ventilation Plus & Servo \\
\hline Proportional Pressure Support & Servo \\
\hline Neurally Adjusted Ventilatory Assist & Servo \\
\hline Assist/Control (Adaptive Flow and I-Time) & Automatic \\
\hline Pressure Regulated Volume Control & Automatic \\
\hline $\begin{array}{l}\text { Volume Controlled Synchronized Mandatory } \\
\text { Ventilation (Adaptive Flow and I-Time) }\end{array}$ & Automatic \\
\hline Mandatory Minute Volume Ventilation & Automatic \\
\hline AutoMode (PRVC - VS) & Automatic \\
\hline Volume Support & Automatic \\
\hline Mandatory Rate Ventilation & Automatic \\
\hline Adaptive Support Ventilation & Automatic \\
\hline SmartCare/PS & Automatic \\
\hline
\end{tabular}

of the pressure waveform is variable. There are 2 forms of manual targeting scheme: set-point and dual.

\section{Set-Point Targeting}

In set-point targeting the operator sets specific target values and the ventilator attempts to deliver them. The simplest examples for volume-control modes would be tidal volume and inspiratory flow. The simplest equation expressing the controller function in volume control is:

$$
\dot{\mathrm{V}}(\mathrm{t})=\mathrm{K}
$$

where $\dot{V}(\mathrm{t})$ represents inspiratory flow as a function of time $(\mathrm{t})$, and $\mathrm{K}$ is the preset constant inspiratory flow.

For pressure-control modes, the operator may set inspiratory pressure and inspiratory time or cycle threshold. The simplest equation expressing the controller function in this case is:

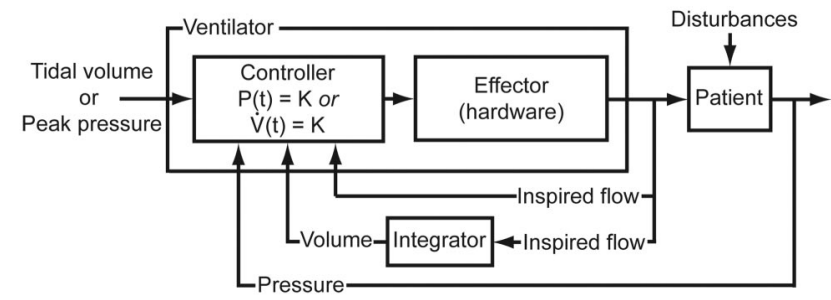

Fig. 2. Control circuit for set-point or dual targeting schemes. In this example, the operator inputs a desired value for inspiratory pressure or inspiratory flow (both for dual targeting). The controller is designed so that either pressure as a function of time $(P(t))$ or flow as a function of time $(\dot{V}(t))$, is constant $(K)$, the set value of inspiratory pressure or flow.

$$
\mathrm{P}(\mathrm{t})=\mathrm{K}
$$

where $\mathrm{P}(\mathrm{t})$ is inspiratory pressure as a function of time $(\mathrm{t})$, and $\mathrm{K}$ is the preset constant inspiratory pressure.

Figure 2 shows a control circuit for the set-point control targeting scheme, for either volume control with a constant flow or pressure control with a constant pressure. Depending on the ventilator, various flow or pressure waveforms may be preset, with correspondingly more complex equations for the controller functions.

\section{Dual Targeting}

As it relates to mechanical ventilation, volume control means that inspired volume, as a function of time, is predetermined by the operator before the breath begins. In contrast, pressure control means that inspiratory pressure as a function of time is predetermined. "Predetermined" in this sense means that either pressure or volume is constrained to a specific mathematical form. In the simple case where either pressure or flow are preset constant values (eg, set-point targeting, as explained above), we can say that they are the independent variables in the equation of motion. The equation of motion for the respiratory system is a general mathematical model of patient-ventilator interaction:

$$
\mathrm{P}(\mathrm{t})=\mathrm{EV}(\mathrm{t})+\mathrm{R} \dot{V}(\mathrm{t})
$$

where $\mathrm{P}(\mathrm{t})$ is inspiratory pressure as a function of time $(\mathrm{t})$, $\mathrm{E}$ is respiratory-system elastance, $\mathrm{V}(\mathrm{t})$ is volume as a function of time, $\mathrm{R}$ is respiratory-system resistance, and $\dot{V}(\mathrm{t})$ is flow as a function of time. Thus, for example, if pressure is the independent variable, then both volume and flow are dependent variables, indicating pressure control. If volume is the independent variable, then pressure is the dependent variable, indicating volume control. Because volume is the integral of flow, if $\dot{V}(t)$ is predetermined, then so is $V(t)$. 
Therefore, for simplicity, we include the case of flow being the independent variable as a form of volume control.

Only one variable (ie, pressure or volume) can be independent at any moment, but a ventilator controller can switch between the two during a single inspiration (see Fig. 2). When this happens the targeting scheme is called dual set-point control or dual targeting. ${ }^{1}$ There are 2 basic ways that ventilators have implemented dual targeting. One way is to start inspiration in volume control and then switch to pressure control if one or more preset thresholds are met (eg, a desired peak airway pressure limit). An example of such a threshold is the operator-set Pmax in Volume Control on the Dräger Evita XL ventilator. The other form of dual targeting is to start inspiration in pressure control and then switch to volume control (eg, if a preset tidal volume has not been met when flow decays to a preset value). ${ }^{25}$ This was originally described as Volume Assured Pressure Support Ventilation, but is currently available only as a mode called Volume Control Assist Control with Machine Volume, in the CareFusion Avea ventilator.

Manual targeting schemes have limited capability to maintain synchrony with patient inspiratory efforts. This can be seen in the equation of motion if a term representing the patient inspiratory force (muscle pressure or $\mathrm{P}_{\text {mus }}$ ) is added:

$$
\mathrm{P}(\mathrm{t})=\mathrm{EV}(\mathrm{t})+\mathrm{R} \dot{V}(\mathrm{t})-\mathrm{P}_{\text {mus }}(\mathrm{t})
$$

For example, with set-point volume control, volume and flow are preset. Therefore, if the patient makes an inspiratory effort (ie, $\mathrm{P}_{\text {mus }}(\mathrm{t})>0$ ), then the equation dictates that transrespiratory-system pressure, $\mathrm{P}(\mathrm{t})$, must fall. Because work is the result of both pressure and volume delivery (ie, work $=\int \mathrm{Pdv}$ ), if pressure decreases, the work the ventilator does on the patient decreases, and hence we have asynchrony of work demand on the part of the patient versus work output on the part of the ventilator.

With set-point pressure control, transrespiratory pressure is preset. Therefore, if the patient makes an inspiratory effort, both volume and flow increase. With constant pressure and increased volume, work per liter for the breath stays constant. While this gives better work synchrony than does volume control, it is still not ideal.

\section{Servo Targeting Schemes}

The term "servo" was coined by Joseph Farcot in 1873 to describe steam-powered steering systems. Later, hydraulic "servos" were used to position anti-aircraft guns on warships. ${ }^{26}$ Servo control specifically refers to a control system that converts a small mechanical motion into one requiring much greater power, using a feedback mechanism. As such, it offers a substantial advantage in terms of

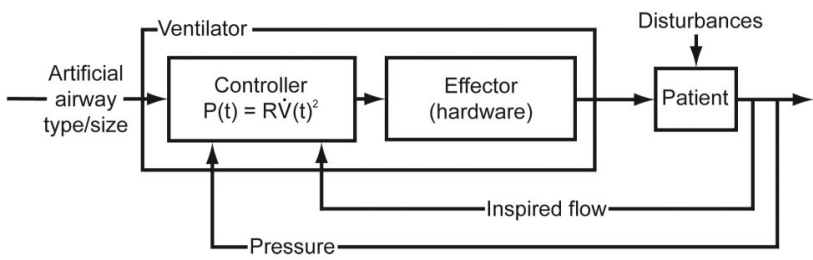

Fig. 3. Control circuit for a servo targeting scheme (eg, Automatic Tube Compensation). The controller is designed so that inspiratory pressure as a function of time $(P(t))$ is proportional to the square of flow as a function of time $\left(\dot{V}(t)^{2}\right)$, with the constant of proportionality being artificial airway resistance $(R)$.

creating ventilation modes capable of a high degree of synchrony with patient breathing efforts. That is, ventilator work output can be made to match patient work demand with a high degree of fidelity. Younes, at the suggestion of Warren Sanborn, stated that Proportional Assist Ventilation (PAV) was analogous to power steering in motor vehicles. ${ }^{27}$ Therefore, we apply the name servo control to targeting schemes in which the ventilator's output automatically follows a varying input. This includes PAV, Automatic Tube Compensation (ATC), and Neurally Adjusted Ventilatory Assist (NAVA), in which the airway pressure signal not only follows but amplifies signals that are surrogates for patient effort (ie, volume, flow, and diaphragmatic electrical signals). Note that the term "servo control" has been loosely used since it was coined to refer to any type of general feedback control mechanism, but we are using it in a very specific manner, as it applies to ventilator targeting schemes.

\section{Automatic Tube Compensation}

ATC is perhaps the simplest example of a servo targeting scheme on a ventilator. The goal of ATC, in terms of patient-ventilator synchrony, is to support the resistive work of breathing through the artificial airway. Figure 3 shows a control circuit for Automatic Tube Compensation. ATC is a form of pressure control, and the mathematical model of the controller relates airway pressure to the inspiratory flow of the patient's spontaneous breath. A spontaneous breath is one in which inspiration is both triggered (started) and cycled (stopped) by the patient. A breath that is either triggered or cycled by the ventilator is a mandatory breath. ${ }^{28}$ The operator inputs the size and type of the artificial airway, and the ventilator uses a look-up table to determine the airway resistance. Then the controller manipulates flow to control pressure according to a mathematical model that sets pressure equal to the product of resistance and the square of (inspiratory or expiratory) flow ${ }^{29,30}$ :

$$
\mathrm{P}(\mathrm{t})=\mathrm{R} \dot{V}(\mathrm{t})^{2}
$$




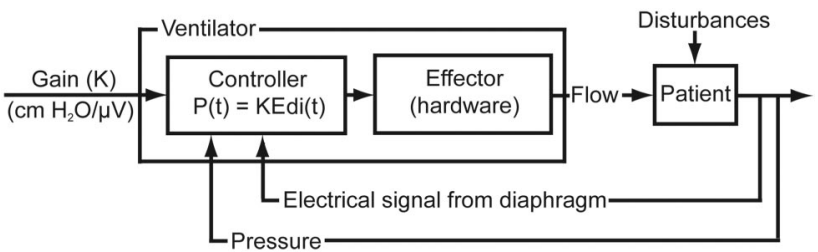

Fig. 4. Control circuit for a servo targeting scheme (eg, Neurally Adjusted Ventilatory Assist). The controller is designed so that inspiratory pressure as a function of time $(\mathrm{P}(\mathrm{t}))$ is proportional to the electrical signal from the diaphragm $(\operatorname{Edi}(t))$, which is also a function of time. The constant of proportionality $(\mathrm{K})$ is the output gain, expressed in $\mathrm{cm} \mathrm{H}_{2} \mathrm{O} / \mu \mathrm{V}$.

where $\mathrm{P}(\mathrm{t})$ is inspiratory pressure relative to end-expiratory pressure as a function of time $(\mathrm{t}), \mathrm{R}$ is the resistance of the artificial airway, and $\dot{V}$ is flow as a function of time. Because airway pressure with ATC is a function of the patient's otherwise unassisted spontaneous inspiratory flow (eg, during CPAP), and because flow is generated by the patient's muscle pressure $\left(\mathrm{P}_{\mathrm{mus}}\right)$, ATC can be thought of as a simple amplifier of patient effort. ${ }^{31}$

\section{Neurally Adjusted Ventilatory Assist}

NAVA is a servo targeting scheme similar to ATC but with more complex requirements for implementation. In terms of patient-ventilator synchrony, NAVA supports both resistive and elastic work of breathing in proportion to the patient's inspiratory effort. With NAVA the controller sets airway pressure to be proportional to $\mathrm{P}_{\text {mus }}$, based on the voltage recorded from diaphragmatic activity measured by sensors embedded in an orogastric tube:

$$
\mathrm{P}(\mathrm{t})=\operatorname{KEdi}(\mathrm{t})
$$

where $\mathrm{P}(\mathrm{t})$ is inspiratory pressure as a function of time $(\mathrm{t})$, $\mathrm{K}$ is the NAVA support level (an amplification factor), and Edi(t) is the electrical signal from the diaphragm as a function of time. The operator inputs the constant of proportionality between voltage and pressure (ie, gain factor). Then the controller sets airway pressure to equal the product of the gain and the Edi. Figure 4 shows a control circuit for NAVA. ${ }^{32}$

\section{Proportional Assist Ventilation}

PAV is a servo targeting scheme that uses a more complex model than ATC or NAVA. In terms of patient-ventilator synchrony, PAV, like NAVA, supports both resistive and elastic work of breathing in proportion to the patient's inspiratory effort, but it uses different feedback signals. PAV is a form of pressure control based on the equation of motion for the respiratory system ${ }^{24}$ in the form:

$$
\mathrm{P}(\mathrm{t})=\mathrm{K}_{1} \mathrm{~V}(\mathrm{t})+\mathrm{K}_{2} \dot{\mathrm{V}}(\mathrm{t})
$$

where inspiratory pressure relative to end-expiratory pressure as a function of time $[\mathrm{P}(\mathrm{t})]$ is the sum of 2 components. The first is the "volume assist" or the amount of elastic load supported (ie, $\mathrm{K}_{1}$ times volume as a function of time $[\mathrm{V}(\mathrm{t})])$. The second component is the "flow assist" or the amount of resistive load supported (ie, $\mathrm{K}_{2}$ times flow as a function of time $[\dot{V}(t)])$. Both volume and flow are used as feedback signals and represent the combined result of patient effort and ventilator support. The values of $K_{1}$ and $K_{2}$ are preset by the operator and represent the supported elastance and resistance, respectively (Fig. 5). Because volume and flow are initiated by the patient's muscle pressure $\left(\mathrm{P}_{\mathrm{mus}}\right)$, the pressure generated by PAV can be thought of as an amplifier of $\mathrm{P}_{\text {mus }}$.

The form of PAV implemented on the Dräger Evita XL ventilator (called Proportional Pressure Support) requires the operator to input desired values for elastance $\left(K_{1}\right)$ and resistance $\left(\mathrm{K}_{2}\right)$ to be supported. ATC can be added to this mode. PAV implemented on the Puritan Bennett 840 ventilator (called PAV Plus) uses a slightly different equation, which automatically calculates the resistance of the artificial airway and combines $\mathrm{K}_{1}$ and $\mathrm{K}_{2}$, such that the operator enters only a single value representing the percentage work of breathing to be supported. PAV Plus also continuously monitors lung mechanics to keep the controller informed of changing values of respiratory-system elastance and resistance. The design differences between Proportional Pressure Support and PAV Plus lead to important performance differences. Figure 6 shows results from our laboratory, indicating that the addition of ATC to Proportional Pressure Support yields a huge variation in the relationship between the work demanded by the patient and the work output by the ventilator. ${ }^{33}$ At an ATC level of $100 \%$, a $30 \%$ increase in patient work resulted in a $200 \%$ increase in ventilator work output. Of equal con-

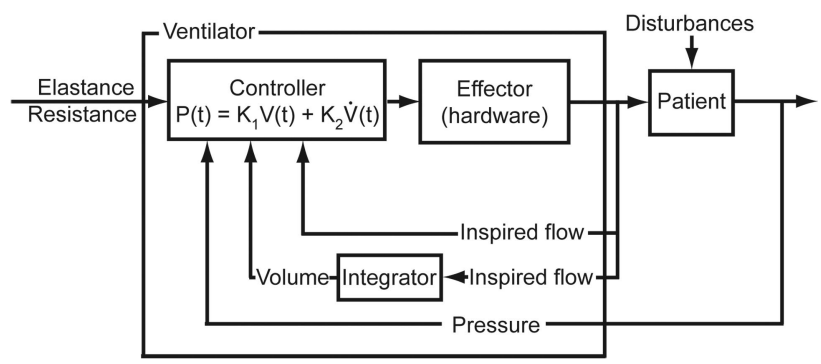

Fig. 5. Control circuit for a servo targeting scheme (eg, Proportional Assist Ventilation). The controller is designed so that inspiratory pressure as a function of time $(P(t))$ is proportional to both volume as a function of time $(\mathrm{V}(\mathrm{t}))$ and flow as a function of time $(\dot{V}(t))$. The constant of proportionality $K_{1}$ represents the amount of elastance to be supported. The constant of proportionality $\mathrm{K}_{2}$ represents the amount of resistance to be supported. 

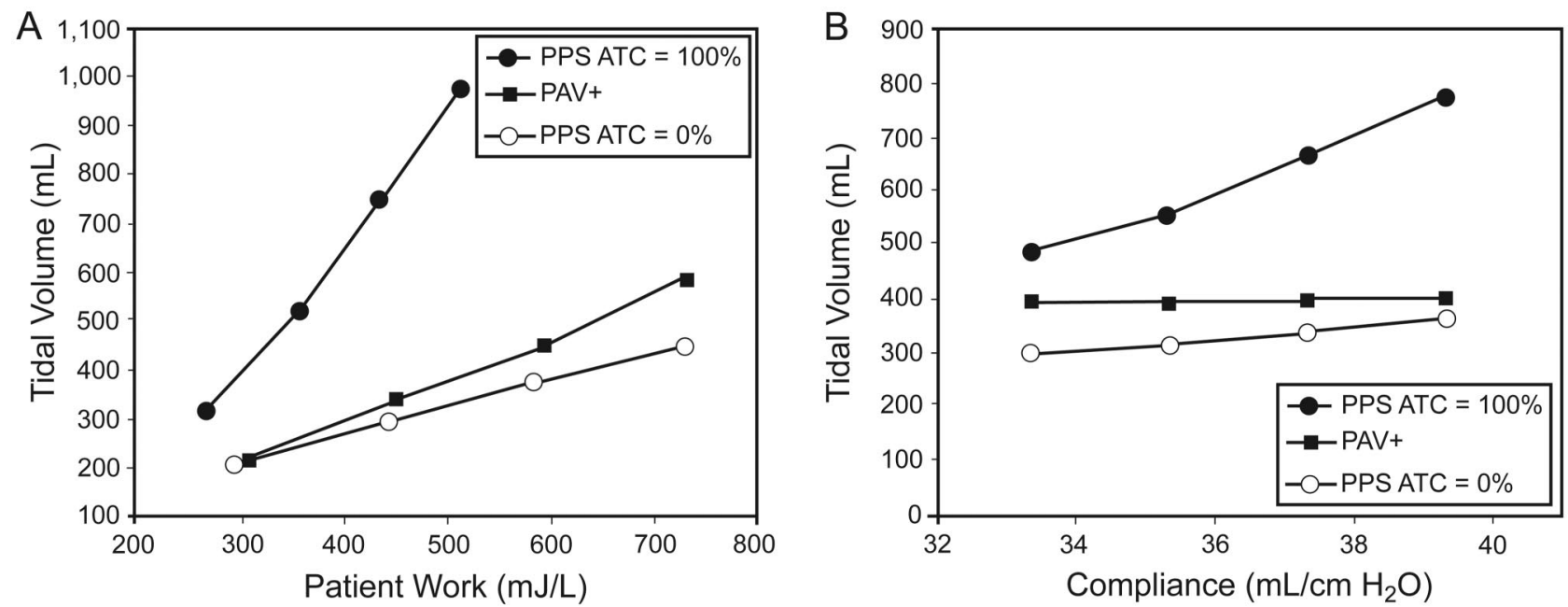

Fig. 6. Comparison of 2 implementations of Proportional Assist Ventilation: Proportional Pressure Support (PPS) (Dräger) and PAV Plus (Covidien). A: Both modes increase ventilator work output as patient work demand increases, but the relationship in PPS is highly variable, depending on the level of Automatic Tube Compensation (ATC) chosen. PAV Plus includes tube compensation as part of the controller function and it is not user adjustable. B: PAV Plus delivers the same tidal volume as compliance changes, because it monitors compliance and changes the controller function. PPS does not monitor compliance and thus overcompensates as compliance increases. This effect is amplified with the use of ATC.

cern, the inability of Proportional Pressure Support to monitor and correct for changes in respiratory-system mechanics can lead to unexpected results. Figure 6 shows that for relatively small increases in respiratory-system compliance (the inverse of elastance) the delivered tidal volume was increased with Proportional Pressure Support but was constant with PAV Plus.

Before concluding this section, we note that the simple didactic construct of "independent versus dependent variable," mentioned above in the section on dual targeting schemes, breaks down in the case of servo targeting schemes. For example, with PAV, pressure depends on volume and flow. At fist thought this might suggest that PAV is a form of volume control. But volume and flow are not predetermined static targets, as in the case of volume control: they are dynamically determined by the patient. Nevertheless, we need to classify PAV and the other servo targeting schemes as either pressure control or volume control. This is accomplished by referring to the general definition of the "control variable" as being the variable that is predetermined by the operator (in this case the ventilator). In the case of the servo targeting schemes, pressure as a function of time, $\mathrm{P}(\mathrm{t})$, is predetermined by specific mathematical models; that is, $\mathrm{P}(\mathrm{t})=\mathrm{R} \dot{V}(\mathrm{t})^{2}$ for ATC, $\mathrm{P}(\mathrm{t})=\mathrm{KEdi}(\mathrm{t})$ for NAVA, and $\mathrm{P}(\mathrm{t})=\mathrm{K}_{1} \mathrm{~V}(\mathrm{t})+\mathrm{K}_{2} \dot{\mathrm{V}}(\mathrm{t})$ for PAV. Therefore we conclude that these servo targeting schemes are forms of pressure control.

\section{Automatic Targeting Schemes}

Automatic targeting schemes allow the ventilator to adjust some set-points according to either a mathematical model derived from known physiologic processes ${ }^{34}$ or some form of artificial intelligence, such as a rule-based expert system, fuzzy-logic, or an artificial neural network. ${ }^{35}$ Of course, it is possible to combine approaches into hybrid systems. ${ }^{36-38}$

Artificial-intelligence systems automate the clinician's heuristics (rules derived from experimentation or experience) and may enforce protocols when humans would falter for various reasons. However, a disadvantage of artificial-intelligence systems is that they have limited transparency, meaning that the way set-points are adjusted is not easily understood because of the complex interaction of many rules. Furthermore, such rules may be subjective (ie, based on expert opinion, leading to increased complexity). Another option is to use mathematical models, which have the advantage of being transparent and objective. ${ }^{22}$ Models may also help the clinician understand the patient's physiologic state, which are represented by the model's parameters. If the parameters are estimated for a particular patient, the model might be used to answer "what if" questions and predict the outcome of different ventilation strategies. ${ }^{39}$ On the other hand, such models can be difficult to derive and can suffer from having too many parameters. ${ }^{40}$

There are 3 general categories of automatic targeting scheme in current use: adaptive, optimal, and intelligent targeting.

\section{Adaptive Targeting}

An adaptive targeting scheme involves modifying the function the controller uses to cope with the fact that the 


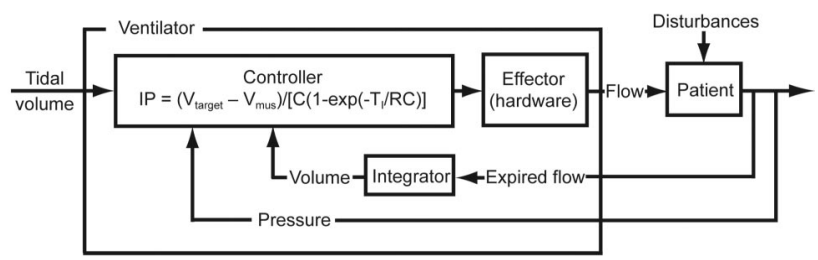

Fig. 7. Control circuit for an adaptive pressure targeting scheme (eg, Pressure Regulated Volume Control). The controller is designed so that inspiratory pressure relative to PEEP (IP) is adjusted to meet the target tidal volume, given changes in resistance $(R)$, compliance $(C)$, and volume $\left(V_{\text {mus }}\right)$ generated by patient effort $\left(P_{\text {mus }}\right)$. IP will increase if $R$ increases or $C$ decreases. IP will decrease if $V_{\text {mus }}$ increases. $T_{1}=$ inspiratory time.

system parameters being controlled are time-varying..$^{41}$ As it applies to mechanical ventilation, adaptive targeting schemes allow the ventilator to set some (or conceivably all) of the targets in response to varying patient conditions. There are currently 4 distinct approaches to basic adaptive targeting, represented by the mode names Pressure Regulated Volume Control, Mandatory Rate Ventilation, Adaptive Flow/Adaptive I-Time, and Mandatory Minute Ventilation. Two advanced forms of adaptive targeting (optimal and intelligent) will be treated separately.

Pressure Regulated Volume Control. Pressure Regulated Volume Control is one example of adaptive targeting of inspiratory pressure, with the goal of providing the flow synchrony of set-point pressure control with the tidal-volume assurance of set-point volume control. One of the concerns with set-point pressure-control ventilation is that it cannot guarantee a minimum tidal volume in the face of changing lung mechanics or patient effort. To solve this problem, Siemens introduced adaptive pressure targeting in a mode they called Pressure Regulated Volume Control. This targeting scheme has also been given the general name adaptive pressure control. ${ }^{42,43}$ The operator inputs a target tidal volume and the controller manipulates the flow, within a breath, to control the inspiratory pressure to a constant value (pressure control). Between breaths the inspiratory pressure is automatically adjusted by the ventilator to achieve the target volume (Fig. 7). Adaptive pressure targeting has been used for both mandatory and spontaneous breaths, and the various modes that use this scheme have been given many different proprietary names by ventilator manufacturers (eg, Covidien uses $\mathrm{VC}+$ and $\mathrm{VV}+$, Dräger uses AutoFlow, and Hamilton uses APV)

To understand what the targeting scheme does, we first note that the target tidal volume has 2 components, one due to the ventilator and the other due to the patient:

$$
\mathrm{V}_{\text {target }}=\mathrm{V}_{\text {vent }}+\mathrm{V}_{\text {mus }}
$$

where $\mathrm{V}_{\text {target }}$ is the tidal volume target set by the operator, $\mathrm{V}_{\text {vent }}$ is the volume delivered by the ventilator-generated pressure, $P(t)$, and $V_{\text {mus }}$ is the volume generated by the patient's muscle pressure as a function of time, $P_{\text {mus }}(t)$, during the inspiratory time (assuming the presence of a patient inspiratory effort). In the simplest case of

$$
\mathrm{P}(\mathrm{t})=\text { constant }=\Delta \mathrm{P}
$$

then

$$
\mathrm{V}_{\text {vent }}=(\mathrm{C} \Delta \mathrm{P})\left(1-\mathrm{e}^{-\mathrm{T}_{\mathrm{I}} / \mathrm{RC}}\right)
$$

where $\mathrm{R}$ is respiratory-system resistance, $\mathrm{C}$ is respiratorysystem compliance, $\Delta \mathrm{P}$ is inspiratory pressure above $\mathrm{PEEP}$, $\mathrm{e}$ is the base of natural logarithms (approximately 2.72), and $T_{I}$ is inspiratory time.

$\mathrm{V}_{\text {mus }}$ is unpredictable because $\mathrm{P}_{\text {mus }}(\mathrm{t})$ is unpredictable. Therefore, we can express the target tidal volume as:

$$
\mathrm{V}_{\text {target }}=(\mathrm{C} \Delta \mathrm{P})\left(1-\mathrm{e}^{-\mathrm{T}_{\mathrm{I}} / \mathrm{RC}}\right)+\mathrm{V}_{\text {mus }}
$$

Solving this equation for $\Delta \mathrm{P}$ gives a simple model for how adaptive targeting automatically adjusts inspiratory pressure:

$$
\Delta \mathrm{P}=\left(\mathrm{V}_{\text {target }}-\mathrm{V}_{\text {mus }}\right) /\left[\mathrm{C}\left(1-\mathrm{e}^{-\mathrm{T}_{\mathrm{I}} / \mathrm{RC}}\right)\right]
$$

This equation predicts that, if $\mathrm{V}_{\text {mus }}$ stays constant, the ventilator will increase $\Delta \mathrm{P}$ if either $\mathrm{R}$ increases or $\mathrm{C}$ decreases (or both). This is intuitively obvious, because if the lungs are stiffer or flow is restricted by narrower airways, then it will take more inspiratory pressure to hit the target tidal volume. Likewise, the ventilator will decrease $\Delta \mathrm{P}$ if either $\mathrm{R}$ decreases or $\mathrm{C}$ increases (or both). On the other hand, the equation shows that the ventilator will decrease $\Delta \mathrm{P}$ if patient inspiratory effort increases (ie, $\mathrm{V}_{\text {mus }}$ increases). This latter effect is what has led some authors to conclude that adaptive pressure targeting is a type of automatic weaning. The problem is that the controller has no way of knowing whether the increase in $\mathrm{V}_{\text {mus }}$ and resultant decrease in inspiratory pressure are appropriate (eg, the patient is recovering from sedation) or inappropriate (eg, $\mathrm{V}_{\text {mus }}$ increasing due to pain or anxiety). Furthermore, the controller cannot distinguish an increase in patient effort (increased $\mathrm{V}_{\text {mus }}$ ) from improved lung mechanics (increase in $\mathrm{C}$ or decrease in $\mathrm{R}$ ). The controller always follows the patient's lead (by decreasing support in response to an increase in effort), whereas the clinician would lead the patient by decreasing support and then observing the patient's response. Therefore, this form of adaptive pressure targeting should not be considered a form of automatic 


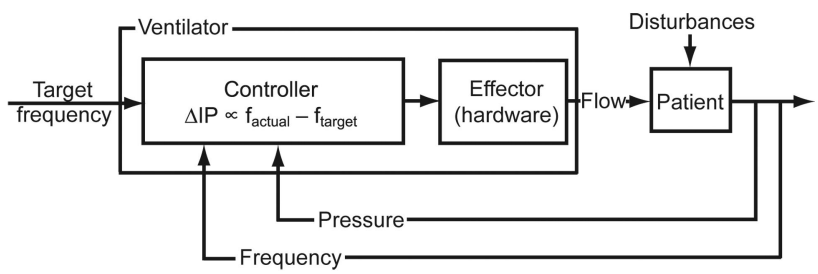

Fig. 8. Control circuit for an adaptive pressure targeting scheme (eg, Mandatory Rate Ventilation). The controller is designed so that inspiratory pressure as a function of time $(\mathrm{P}(\mathrm{t}))$ is proportional to the difference between the target and the actual spontaneous breathing frequencies $\left(f_{\text {target }}\right.$ and $\left.f_{\text {actual }}\right)$. If the difference is positive, the inspiratory pressure is increased. If the difference is negative, the inspiratory pressure is reduced. Thus, the system converges on a Pressure Support level that should keep the patient comfortable, assuming the target frequency is selected correctly.

weaning per se, although it may have that effect in certain situations.

Mandatory Rate Ventilation. An interesting variation of adaptive targeting is Mandatory Rate Ventilation, on the Taema-Horus ventilator (Air Liquide, Antony, France), ${ }^{44}$ which is a form of pressure support in which the inspiratory pressure is automatically adjusted based on a target value for the patient's spontaneous breath frequency (Fig. 8). The operator sets a target frequency and the controller adjusts the inspiratory pressure (ie, the pressuresupport level) in proportion to the difference between the actual and target breath frequencies:

$$
\Delta(\Delta \mathrm{P}) \propto \mathrm{f}_{\text {actual }}-\mathrm{f}_{\text {target }}
$$

where $\Delta \mathrm{P}$ is inspiratory pressure relative to PEEP, and $\Delta(\Delta \mathrm{P})$ is the change in inspiratory pressure made by the ventilator in response to changes in the patient's spontaneous breathing frequency. The operator-set target frequency, $\mathrm{f}_{\text {target }}$ is the spontaneous respiratory frequency the patient is expected to perform when comfortable. The ventilator compares the average actual frequency from the last 4 breaths $\left(f_{\text {actual }}\right)$ to the target frequency. If $f_{\text {actual }}$ is higher than the $f_{\text {target }}$, the inspiratory pressure is automatically increased. If the $f_{\text {actual }}$ is lower than the $f_{\text {target }}$, the inspiratory pressure is automatically decreased. The basic idea is that when the inspiratory pressure is correctly adjusted, the patient will have an acceptable ventilatory frequency (eg, 15-25 breaths/min) and will be breathing comfortably. When the pressure is too low, the patient's frequency will increase and vice versa. Hence, the controller attempts to keep the patient in a comfortable range of ventilatory assistance as assessed by frequency, assuming the operator has selected the appropriate target frequency.

Adaptive Flow and Adaptive I-Time. The General Electric Versamed iVent ventilator has 2 unique adaptive tar- geting schemes available in volume-control modes called Adaptive Flow and Adaptive I-Time. Working together with a preset tidal volume, these algorithms automatically adjust the inspiratory time and inspiratory flow to maintain a target inspiratory-expiratory ratio of 1:2 (considered a normal value) in the face of a variable breathing frequency on the part of the patient (Fig. 9). This action can be described by the equation:

$$
\left(\mathrm{V}_{\mathrm{T}} / \dot{\mathrm{V}}_{\mathrm{I}}\right):\left(1 / \mathrm{f}-\mathrm{T}_{\mathrm{I}}\right)=1: 2
$$

where $\mathrm{V}_{\mathrm{T}}$ is the preset tidal volume, $\dot{\mathrm{V}}_{\mathrm{I}}$ is the ventilator adjustable inspiratory flow (constant during a given breath), $\mathrm{f}$ is the patient's spontaneous breathing frequency and $T_{\mathrm{I}}$ is the ventilator adjustable inspiratory time. For example, as the frequency increases, the ventilatory period (inspiratory time plus expiratory time, or 1/f) decreases. However, because $V_{T}$ and $\dot{V}_{I}$ are preset before the breath, the $T_{I}$ is preset, hence the inspiratory-expiratory ratio increases. In an effort to maintain the target inspiratory-expiratory ratio of $1: 2$, the ventilator will respond by automatically decreasing the $T_{I}$ of the next breath. However, to maintain the target $\mathrm{V}_{\mathrm{T}}$, it must also increase $\dot{\mathrm{V}}_{\mathrm{I}}\left(\mathrm{ie}, \mathrm{V}_{\mathrm{T}}=\dot{\mathrm{V}}_{\mathrm{I}} \times \mathrm{T}_{\mathrm{I}}\right)$. In summary, $\mathrm{V}_{\mathrm{T}}$ is preset by the operator, $\mathrm{f}$ is determined by the patient, $\dot{\mathrm{V}}_{\mathrm{I}}$ and $\mathrm{T}_{\mathrm{I}}$ are automatically adjusted by the ventilator between breaths to maintain a target inspiratoryexpiratory ratio of $1: 2$.

Mandatory Minute Ventilation. The idea of automatically adjusting the ventilation pattern to maintain a constant minute volume was first described in 1977.45 As implemented, for example, on the Dräger Evita XL ventilator, Mandatory Minute Ventilation is a form of volumecontrol intermittent mandatory ventilation. The operator presets the target minute ventilation by setting tidal volume and frequency. The ventilator then monitors the total minute ventilation as the sum of the minute ventilations

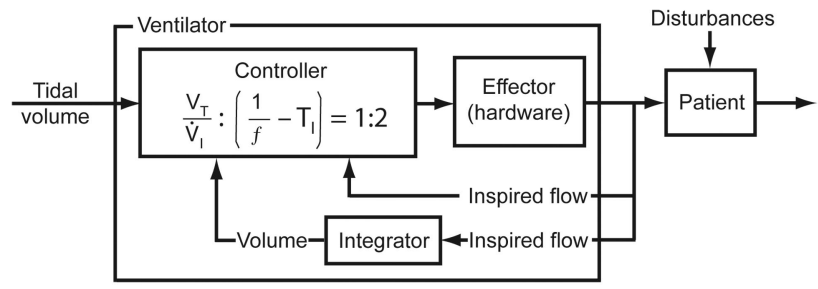

Fig. 9. Control circuit for an adaptive pressure targeting scheme (eg, Adaptive Flow and Adaptive I-Time). The controller is designed so that for a preset tidal volume, inspiratory time and flow are adjusted automatically, in the face of a changing breathing frequency, to maintain the inspiratory-expiratory ratio at 1:2. $\mathrm{V}_{\mathrm{T}}=$ tidal volume. $\dot{\mathrm{V}}=$ inspiratory flow (constant during a given breath). $f=$ patient's spontaneous breathing frequency. $T_{1}=$ inspiratory time. inspiratory-expiratory ratio is the ratio of inspiratory time to expiratory time. 
generated by mandatory and spontaneous breaths (Fig. 10). The controller function can be expressed as:

$$
\mathrm{MV}_{\text {total }}=\mathrm{MV}_{\text {mandatory }}+\mathrm{MV}_{\text {spontaneous }}
$$

where MV is minute ventilation. If the total minute ventilation is below the target value, the mandatory breath frequency will increase. However, as long as the spontaneous minute ventilation is at least equal to the target value, mandatory breaths will be suppressed. In this way, the proportion of the total minute ventilation generated by spontaneous breaths can range from $0 \%$ to $100 \%$. As with adaptive pressure targeting schemes, Mandatory Minute Ventilation has been called a mode of automatic weaning. However, Mandatory Minute Ventilation has the same limitations mentioned above, in that the suppression of mandatory breaths may be due to an inappropriate increase in spontaneous breaths, perhaps even with a rapid, shallow pattern that actually decreases minute alveolar ventilation. The Hamilton Veolar ventilator used a variation of this targeting scheme by making Mandatory Minute Ventilation a form of adaptive pressure support. The target minute ventilation was maintained by automatic adjustment of inspiratory pressure. That mode was replaced by Adaptive Support Ventilation (ASV) (see optimal targeting below) on newer Hamilton ventilators.

\section{Optimal Targeting}

Optimal targeting is an advanced form of adaptive targeting. ${ }^{46}$ Optimal targeting in this context means that the ventilator controller automatically adjusts the targets of the ventilatory pattern to either minimize or maximize some overall performance characteristic.

Adaptive Support Ventilation. ASV, on the Hamilton ventilators, is the only commercially available mode to date that uses optimal targeting. This targeting scheme was first described by Tehrani in 1991,47,48 and was designed to minimize the work rate of breathing, mimic natural

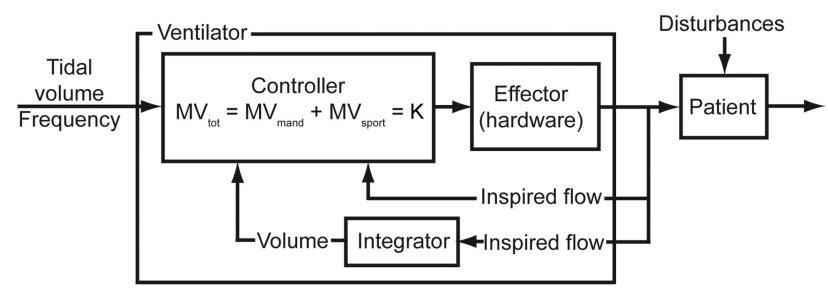

Fig. 10. Control circuit for an adaptive pressure targeting scheme (eg, Mandatory Minute Ventilation). The controller is designed so that the sum of the mandatory minute ventilation (MV) and the spontaneous $\mathrm{MV}$ is equal to the preset value $(\mathrm{K})$ determined by the preset tidal volume and frequency.

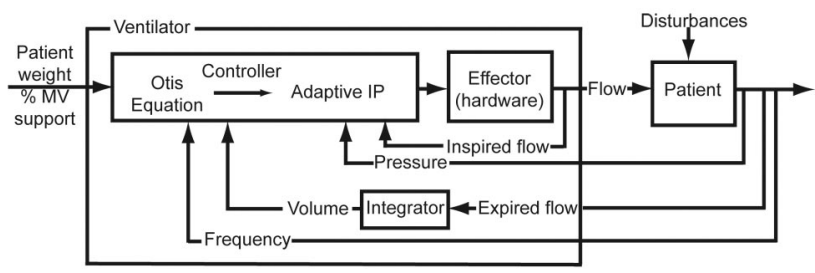

Fig. 11. Control circuit for an optimum targeting scheme (eg, Adaptive Support Ventilation). The controller is designed to select a frequency and tidal volume that minimizes the work-rate of breathing. The tidal volume is delivered using the adaptive pressure control targeting scheme in Figure 7. MV = minute ventilation. IP = inspiratory pressure.

breathing, stimulate spontaneous breathing, and reduce weaning time. ${ }^{24}$ The operator inputs the patient's weight, from which the ventilator estimates the required minute alveolar ventilation, assuming a normal dead-space fraction. Next, an optimum frequency is calculated based on work by Otis et al, ${ }^{49}$ that predicts a frequency resulting in the least mechanical power (work rate) ${ }^{24}$ :

$$
\mathrm{f}=\frac{-1+\sqrt{1+4 \pi^{2} R C_{E}\left(\frac{M V-f V_{D}}{V_{D}}\right)}}{1+2 \pi^{2} R C_{E}}
$$

where MV is predicted minute ventilation (in $\mathrm{L} / \mathrm{min}$ ) based on patient weight and the setting for percent-of-predicted MV to support, $\mathrm{V}_{\mathrm{D}}$ is predicted dead space (in $\mathrm{L}$ ) based on patient weight, $\mathrm{RC}_{\mathrm{E}}$ is the expiratory time constant calculated as the slope of the expiratory flow-volume curve, and $\mathrm{f}$ is the computed optimal frequency (in breaths/min). The target tidal volume is calculated as MV/f. The control circuit for ASV shows that the controller uses the Otis equation to set the tidal volume (Fig. 11). As with simple adaptive pressure targeting, the inspiratory pressure within a breath is controlled to achieve a constant value, and between breaths the inspiratory pressure is adjusted to achieve a target tidal volume. However, unlike simple adaptive pressure targeting, the target is not set by the operator, but rather it is estimated by the ventilator in response to changes in respiratory-system mechanics and patient effort. Individual pressure-targeted breaths may be mandatory (time-triggered and time-cycled) or spontaneous (flowtriggered and flow-cycled).

ASV adds some expert rules that put safety limits on frequency and tidal-volume delivery and reduce the risk of auto-PEEP. In that sense, this mode may be considered an intelligent targeting scheme or, more appropriately, a hybrid system (ie, using a mathematical model and artificial intelligence). 


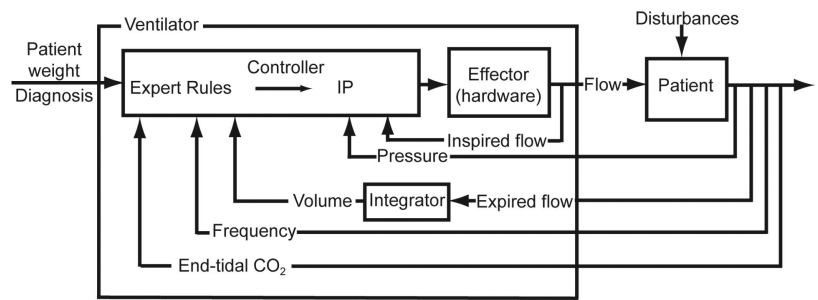

Fig. 12. Control circuit for an intelligent targeting scheme (eg, SmartCare/PS). The controller is designed to identify automatically adjust the inspiratory pressure relative to PEEP (IP) to keep the patient in a "zone of comfort," defined in terms of the instantaneous values of tidal volume, frequency and end-tidal $\mathrm{CO}_{2}$.

\section{Intelligent Targeting Schemes}

Intelligent targeting is another form of adaptive targeting, which uses artificial-intelligence techniques. ${ }^{50}$

\section{SmartCare/PS}

SmartCare/PS on the Dräger XL ventilator is the only ventilation mode commercially available to date in the United States with a targeting scheme that relies entirely on a rule-based expert system. SmartCare/PS is a specialized form of pressure support that is designed for true (ie, ventilator-led) automatic weaning. The SmartCare/PS controller uses predefined acceptable ranges for spontaneous breathing frequency, tidal volume, and end-tidal carbon dioxide tension to automatically adjust the inspiratory pressure to maintain the patient in a "respiratory zone of comfort" ${ }^{51}$ (Fig. 12).

The SmartCare/PS system divides the control process into 3 steps. The first step is to stabilize the patient within the "zone of respiratory comfort," defined as combinations of tidal volume, respiratory frequency and end-tidal $\mathrm{CO}_{2}$ defined as acceptable by the artificial-intelligence program for the operator-set patient diagnosis (ie, COPD or neuromuscular disorder). The second step is to progressively decrease the inspiratory pressure while making sure the patient remains in the "zone." The third step tests readiness for extubation by maintaining the patient at the lowest level of inspiratory pressure, which depends on the type of artificial airway (endotracheal tube vs tracheostomy tube), the type of humidifier (heat-and-moisture exchanger vs heated humidifier), and the use of Automatic Tube Compensation. Once the lowest level of inspiratory pressure is reached, a one-hour observation period is started, during which the patient's breathing frequency, tidal volume, and end-tidal $\mathrm{CO}_{2}$ are monitored. Upon successful completion of this step (essentially a spontaneous breathing trial), a message on the screen suggests that the clinician "consider separation" of the patient from the ventilator. This method of automatic weaning reduced the duration of mechanical ventilation and intensive care unit stay in a multicenter randomized controlled trial. ${ }^{52}$ However, the advantage of artificial intelligence may be less noticeable in environments where natural intelligence is plentiful. Rose et al recently concluded that "substantial reductions in weaning duration previously demonstrated were not confirmed when the SmartCare/PS system was compared to weaning managed by experienced critical care specialty nurses, using a 1:1 nurse-to-patient ratio. The effect of SmartCare/PS may be influenced by the local clinical organizational context." ${ }^{53}$

\section{Caveats}

All closed-loop control systems are only as good as their feedback signals. For example, if adaptive pressure targeting schemes have inaccurate feedback information about target volume, due to leaks, then the system will not work properly and a more primitive system (eg, set-point) must be used. If a servo system such as NAVA cannot obtain an Edi signal, it reverts back to a set-point mode. For systems that rely on physiologic models, the ventilator must be able to obtain the required model parameters. For example, if a patient has a high respiratory drive, PAV Plus may not be able to calculate respiratory-system compliance (using a brief inspiratory hold) and thus will not be able to properly control airway pressure. In the case of mathematical models, the model assumptions must reasonably fit the actual patient conditions. For example, ASV assumes a normal ratio of dead space to tidal volume and a normal minute ventilation requirement. If these assumptions do not apply to the patient at hand, the mode will not work as expected. Another example is SmartCare/PS. If the patient is not ready to wean, SmartCare/PS is not the right mode, because its rule-based system is designed for patients who can tolerate repeated reductions in support. SmartCare/PS also assumes a "normal" serum bicarbonate level, which may not be a correct assumption in people living at high altitudes. ${ }^{54}$ If anything, the more advanced the mode, the more the need for vigilance and understanding on the part of clinicians: hence this paper.

\section{Summary}

A major problem facing clinicians, educators, and even vendors, related to ventilation modes, is the vast proliferation of names and the lack of a standardized approach to understanding them. A key component of a ventilationmode taxonomy is a set of concepts that succinctly describe the operation of closed-loop control schemes in ventilators. Fortunately, the multitude of modes commercially available today can be described with only 6 targeting schemes (set-point, dual, servo, adaptive, optimal, and intelligent, Table 3), which serve the 3 primary goals of mechanical ventilation: safety, comfort, and liberation (Ta- 
Table 3. Targeting Schemes

\begin{tabular}{l}
\hline \hline Manual \\
Set-point \\
Dual \\
Servo \\
Simple servo \\
Advanced servo \\
Automatic \\
Adaptive \\
Simple adaptive \\
Optimal \\
Intelligent \\
\hline
\end{tabular}

ble 4). The basic operation of the 6 schemes may be understood by clinicians without any engineering background, yet their descriptions may provide clinicians and engineers with a better means to communicate. The way that targeting schemes contribute to a taxonomy of modes has been described elsewhere, ${ }^{28}$ and is illustrated in Table 5.

Clearly, closed-loop control of mechanical ventilators is evolving at a rapid pace. The United States Food and Drug Administration's recent acceptance of intelligent targeting schemes such as ASV and SmartCare/PS has paved the way for even more sophisticated systems. Indeed, in the not too distant future the concept of a discrete "mode" or targeting system may become obsolete. As ventilators become more intelligent and able to adapt to a broader range of feedback signals indicating changing patient requirements, the ventilatory patterns will become fluid and interchangeable. We would go so far as to predict that the paradigm will change from the current one, "set the mode

Table 4. Goals and Objectives of Mechanical Ventilation

\begin{tabular}{l}
\hline \hline Promote Safety \\
Optimize ventilation-perfusion of the lung \\
Maximize alveolar ventilation \\
Minimize shunt \\
Optimize pressure/volume curve \\
Minimize tidal volume \\
Maximize compliance \\
Promote Comfort \\
Optimize patient-ventilator synchrony \\
Maximize trigger/cycle synchrony \\
Minimize auto-PEEP \\
Maximize flow synchrony \\
Coordinate mandatory and spontaneous breaths \\
Optimize work demand versus work delivered \\
Minimize inappropriate shifting of work from ventilator to patient \\
Promote Liberation \\
Optimize the weaning experience \\
Minimize adverse events \\
Minimize duration of ventilation
\end{tabular}

Table 5. Outline of a Ventilation Mode Taxonomy, Showing the Contribution of Targeting Schemes*

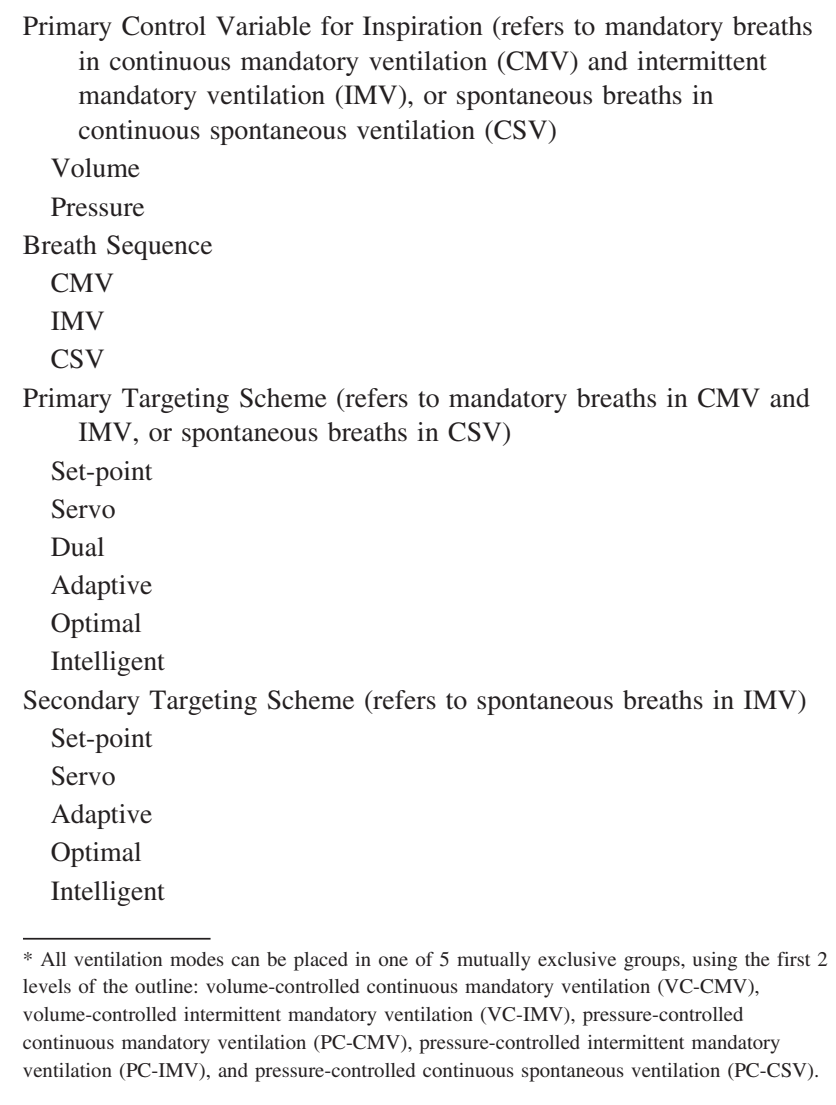

and monitor the outcome," to "set the outcome and monitor the mode." Modes such as "Assist/Control" and "SIMV" will be transitory states instead of preset patterns, and hence the way we think about setting ventilators, modes, and the operator-interface paradigms, must change.

Nevertheless, there have been very few randomized controlled trials exploring the use of advanced targeting schemes, and in those trials (eg, of PAV, ATC, and SmartCare) superiority has not been clearly (nor robustly) demonstrated. Further such studies would be expensive and time-consuming, and might never be performed. That said, the absence of such studies should imbue the reader with a healthy dose of skepticism. Greater complexity of ventilation modes may be better, but we don't know for sure. This is also relevant because we know that poor patientventilator interaction is associated with poor outcomes, but whether patient-ventilator interaction is the cause of those poor outcomes remains uncertain.

The technical developments described in this paper will demand even higher levels of understanding and skill from clinicians, just as automated flight controls have placed higher training demands on pilots. We trust that such future developments do not instill a fear of human reason 
being replaced by machine intelligence, nor a false sense of security such that we "fall asleep at the wheel."

\section{Glossary}

Adaptive targeting scheme. Feedback control system in which the ventilator determines some (or conceivably all) of the targets in response to changes in patient-derived data.

Automatic targeting scheme. Feedback control system that allows the ventilator to set some or all of the ventilatory targets using either mathematical models of physiologic processes or artificial-intelligence algorithms.

Closed-loop control. The use of a feedback signal to adjust the output of a system.

Dual targeting scheme. Feedback control in which the ventilator switches between volume control and pressure control during a single inspiration.

Equation of motion for the respiratory system. A mathematical model of patient-ventilator interaction. The simplest version of this equation, assuming passive inspiration and no auto-PEEP is

$$
\mathrm{P}(\mathrm{t})=\mathrm{EV}(\mathrm{t})+\mathrm{R} \dot{V}(\mathrm{t})
$$

where $\mathrm{P}(\mathrm{t})$ is inspiratory pressure as a function of time, $\mathrm{E}$ is respiratory-system elastance, $\mathrm{V}(\mathrm{t})$ is volume as a function of time, $\mathrm{R}$ is respiratory-system resistance, and $\dot{V}(\mathrm{t})$ is flow as a function of time.

Intelligent targeting scheme. Targeting schemes that use artificial-intelligence techniques such as rule-based expert systems, fuzzy logic and artificial neural networks.

Mandatory breath. A breath in which inspiration is triggered (started) or cycled (stopped) by the ventilator (or both).

Manual targeting scheme. Feedback control system that requires the operator to adjust all the target values.

Ventilation mode. A predetermined pattern of interaction between a mechanical ventilator and the system being ventilated (eg, a patient); a specific combination of control variable, breath sequence, and targeting scheme.

Optimal targeting scheme. Feedback control system in which the ventilator automatically adjusts the targets to either minimize or maximize some overall performance characteristic.

Pressure control. A general category of ventilation modes in which inspired pressure as a function of time is predetermined before the breath begins. For simple pressure-control modes (eg, pressure support), pressure is the independent variable and volume and flow are the dependent variables in the equation of motion for the respiratory system.
Servo targeting scheme. Feedback control system in which the operator sets the parameters of a mathematical model that drives the ventilator output to follow a dynamic signal.

Set-point targeting scheme. Feedback control system in which the operator sets specific target values.

Spontaneous breath. A breath in which inspiration is both triggered (started) and cycled (stopped) by the patient.

Target. A predetermined goal during inspiration or expiration (eg, inspiratory flow or average tidal volume).

Targeting scheme. Feedback control system used by a mechanical ventilator to deliver a specific ventilatory pattern; a key component of a ventilation mode.

Tidal pressure. The change in transalveolar pressure (the pressure in the alveolar region minus the pressure in the pleural space) associated with the delivery of a tidal volume. In pressure-control modes the tidal pressure is estimated as peak airway pressure minus PEEP. In volume-control modes it is estimated as plateau pressure (ie, pressure during an inspiratory hold) minus PEEP. Tidal pressure is a useful parameter when switching between volume control and pressure control and attempting to adjust ventilator settings to maintain the same alveolar ventilation. For example, when switching from volume control to pressure control, suppose the plateau pressure in volume control is $20 \mathrm{~cm} \mathrm{H}_{2} \mathrm{O}$ and PEEP is $5 \mathrm{~cm} \mathrm{H}_{2} \mathrm{O}$. The tidal pressure is $20-5=15 \mathrm{~cm} \mathrm{H}_{2} \mathrm{O}$. Thus, to achieve approximately the same tidal volume in pressure control, inspiratory pressure should be set at $15 \mathrm{~cm} \mathrm{H}_{2} \mathrm{O}$ above PEEP, and inspiratory time should be at least 3 timeconstants long to allow equilibration of airway pressure with alveolar pressure.

Volume control. A general category of ventilation modes in which inspired volume (or flow), as a function of time, is predetermined before the breath begins. For simple volume-control modes (eg, Assist/Control or SIMV) volume is the independent variable and pressure is the dependent variable in the equation of motion for the respiratory system.

\section{REFERENCES}

1. Branson RD, Davis K Jr. Dual control modes: combining volume and pressure breaths. Respir Care Clin N Am 2001;7(3):397-408.

2. Branson RD, Johannigman JA, Campbell RS, Davis K Jr. Closedloop mechanical ventilation. Respir Care 2002;47(4):427-451.

3. Navalesi P, Costa R. New modes of mechanical ventilation: proportional assist ventilation, neurally adjusted ventilatory assist, and fractal ventilation. Curr Opin Crit Care 2003;9(1):51-58.

4. Branson R. Understanding and implementing advances in ventilator capabilities. Curr Opin Crit Care 2004;10(1):23-32.

5. Branson RD, Johannigman JA. What is the evidence base for the newer ventilation modes? Respir Care 2004;49(7):742-60.

6. Snow TM, Brandon DH. A nurse's guide to common mechanical ventilation techniques and modes used in infants: nursing implications. Adv Neonatal Care 2007;7(1):8-21. 
7. Wysocki M, Brunner JX. Closed-loop ventilation: an emerging standard of care? Crit Care Clin 2007;23(2):223-240.

8. Branson RD, Davis K Jr. Does closed loop control of assist control ventilation reduce ventilator-induced lung injury? Clin Chest Med 2008;29(2):343-350.

9. Burns KE, Lellouche F, Lessard MR. Automating the weaning process with advanced closed-loop systems. Intensive Care Med 2008; 34(10):1757-1765.

10. Santanilla JI, Daniel B, Yeow ME. Mechanical ventilation. Emerg Med Clin North Am 2008;26(3):849-862.

11. Lellouche F, Brochard L. Advanced closed loops during mechanical ventilation (PAV, NAVA, ASV, SmartCare). Best Pract Res Clin Anaesthesiol 2009;23(1):81-93.

12. Johannigman JA, Muskat P, Barnes S, Davis K, Branson RD. Autonomous control of ventilation. J Trauma 2008;64(4 Suppl):S302-S320.

13. Puri N, Puri V, Dellinger RP. History of technology in the intensive care unit. Crit Care Clin 2009;25(1):185-200.

14. Donn SM. Neonatal ventilators: how do they differ? J Perinato. 2009;29(Suppl 2):S73-S78.

15. Hummler H, Schulze A. New and alternative modes of mechanical ventilation in neonates. Semin Fetal Neonatal Med 2009;14(1):42-48.

16. Branson RD, Johannigman JA. Innovations in mechanical ventilation. Respir Care 2009;54(7):933-947.

17. Keszler M. State of the art in conventional mechanical ventilation. J Perinatol 2009;29(4):262-275.

18. Cairo JM, Pilbeam SP. Mosby's respiratory care equipment, 8th edition. St Louis: Mosby Elsivier; 2009.

19. Chatburn RL. Computer control of mechanical ventilation. Respir Care 2004;49(5):507-515.

20. Pauldine R, Beck G, Salinas J, Kaczka DW. Closed-loop strategies for patient care systems. J Trauma 2008;64(4 Suppl):S289-S294.

21. Zaleski JR. Integrating device data into the electronic medical record. Erlangen, Germany: Publicis; 2010:209-234.

22. Martinoni EP, Pfister ChA, Stadler KS, Schumacher PM, Leibundgut D, Bouillon T, et al. Model-based control of mechanical ventilation: design and clinical validation. Br J Anaesth 2004;92(6):800-807.

23. Tehrani FT. Automatic control of mechanical ventilation. Part 1: Theory and history of the technology. J Clin Monit Comput 2008; 22(6):409-415.

24. Tehrani FT. Automatic control of mechanical ventilation. Part 2: The existing techniques and future trends J Clin Monit Comput 2008; 22(6):417-424.

25. Amato MB, Barbas CS, Bonassa J, Saldiva PH, Zin WA, de Carvalho $C R$. Volume-assured pressure support ventilation (VAPSV): a new approach for reducing muscle workload during acute respiratory failure. Chest 1992;102(4):1225-1234.

26. Wikipedia contributors. Feedback. http://en.wikipedia.org/wiki/feed back. Accessed November 3, 2010.

27. Younes M. Porportional assist ventilation, a new approach to ventilatory support. Theory. Am Rev Respir Dis 1992;145(1):114-120.

28. Chatburn RL. Classification of ventilator modes: update and proposal for implementation. Respir Care 2007;52(3):301-323.

29. Guttmann J, Eberhard L, Fabry B, Bertschmann W, Wolff G. Continuous calculation of intratracheal pressure in tracheally intubated patients. Anesthesiology 1993;79(3):503-513.

30. Elsasser S, Guttmann J, Stocker R, Mols G, Priebe HJ, Haberthür C. Accuracy of automatic tube compensation in new-generation mechanical ventilators. Crit Care Med 2003;31(11):2619-2626.

31. Unoki T, Serita A, Grap MJ. Automatic tube compensation during weaning from mechanical ventilation: evidence and clinical implications. Crit Care Nurse 2008;28(4):34-42.

32. Sinderby C, Navalesi P, Beck J, Skrobik Y, Comtois N, Friberg S, et al. Neural control of mechanical ventilation. Nat Med 1999;5(12): 1433-1436.
33. Chatburn RL, Wear JL. Comparison of two different proportional assist ventilation algorithms (abstract). Respir Care 2009;54(11):1583.

34. Tehrani FT. Critiquing treatment and setting ventilatory parameters by using physiological modeling. Conf Proc IEEE Eng Med Biol Soc 2009;2009:286-288.

35. Tzavaras A, Weller PR, Spyropoulos B. A neuro-fuzzy controller for the estimation of tidal volume and respiration frequency ventilator settings for COPD patients ventilated in control mode. Conf Proc IEEE Eng Med Biol Soc 2007;2007:3765-3768.

36. Kwok HF, Linkens DA, Mahfouf M, Mills GH. SIVA: a hybrid knowledge-and-model-based advisory system for intensive care ventilators. IEEE Trans Inf Technol Biomed 2004;8(2):161-172.

37. Lozano S, Möller K, Brendle A, Gottlieb D, Schumann S, Stahl CA, Guttmann J. AUTOPILOT-BT: a system for knowledge and model based mechanical ventilation. Technol Health Care 2008;16(1):1-11.

38. Wang A, Mahfouf M, Mills GH, Panoutsos G, Linkens DA, Goode $\mathrm{K}$, et al. Intelligent model-based advisory system for the management of ventilated intensive care patients: hybrid blood gas patient model. Comput Methods Programs Biomed 2010;99(2):195-207.

39. Rees SE, Allerød C, Murley D, Zhao Y, Smith BW, Kjaergaard S, et al. Using physiological models and decision theory for selecting appropriate ventilator settings. J Clin Monit Comput 2006;20(6):421-429.

40. Sundaresan A, Yuta T, Hann CE, Chase JG, Shaw GM. A minimal model of lung mechanics and model-based markers for optimizing ventilator treatment in ARDS patients. Comput Methods Programs Biomed 2009;95(2):166-180.

41. Wikipedia contributors. Adaptive control http://en.wikipedia.org/ wiki/adaptive_control. Accessed November 3, 2010.

42. Mireles-Cabodevila E, Diaz-Guzman E, Heresi GA, Chatburn RL. Alternative modes of mechanical ventilation: a review for the hospitalist. Cleve Clin J Med 2009;76(7):417-430.

43. Branson RD, Chatburn RL. Controversies in the critical care setting. Should adaptive pressure control modes be utilized for virtually all patients receiving mechanical ventilation? Respir Care 2007;52(4):478488.

44. Taniguchi C, Eid RC, Saghabi C, Souza R, Silva E, Knobel E, et al. Automatic versus manual pressure support reduction in the weaning of post-operative patients: a randomised controlled trial. Crit Care 2009;13(1):R6.

45. Hewlett AM, Platt AS, Terry VG. Mandatory minute volume. Anesthesia 1977;32(2):163-169.

46. Stengel RF. Optimal control and estimation. Mineola, NY: Dover Publications; 1994.

47. Tehrani FT. Method and apparatus for controlling an artificial respiratory. US patent 4,986,268, issued January 22, 1991.

48. Tehrani FT. Automatic control of an artificial respirator. Proc IEEE EMBS Conf 1991;13:1738-1739.

49. Otis AB, Fenn WO, Rahn H. Mechanics of breathing in man. J Appl Physiol 1950;2(11):592-607.

50. Wikipedia contributors. Intelligent control. http://en.wikipedia.org/ wiki/intelligent_control. Accessed November 3, 2010.

51. Rose L, Presneill JJ, Cade JF. Update in computer-driven weaning from mechanical ventilation. Anesth Intensive Care 2007;35(2):213-221.

52. Lellouche F, Mancebo J, Jolliet P, Roeseler J, Schortgen F, Dojat M, et al. A multicenter randomized trial of computer-driven protocolized weaning from mechanical ventilation. Am J Respir Crit Care Med 2006;174(8):894-900.

53. Rose L, Presneill JL, Johnston L, Cade JF. A randomised, controlled trial of conventional versus automated weaning from mechanical ventilation using SmartCare/PS. Intensive Care Med 2008;34(10): 1788-1795.

54. Maldonado PA, Díaz UC, Unzueta AS. SmartCare closed-loop system and the altitude problem. Intensive Care Med 2009;35(4): 753. 


\section{Discussion}

Epstein: I like the idea of your ranking system. You seem to make the assumption that all those boxes are equivalent, that there's no weighting of importance, so gas exchange and protecting the lung and liberation are all the same. It may be true, but it also may not be true, and it also may depend upon the patient. Clearly, protecting the lung is important in several kinds of patients, but not in all kinds of patients.

Chatburn: That's exactly true. The problem is that once you get into that kind of multivariate decision analysis and weaning factors based on patient conditions, it becomes unmanageable. I just wanted to show that there was a generalized rational approach in ranking these things, and it would be an interesting academic exercise to see how far you could carry that. In fact, you might even come up with an artificialintelligence program to run it based on the situation and the things you felt were important in that particular case.

MacIntyre: I want to follow up on Scott's point, because I think it's incredibly important. A number of years ago at a conference, Art Slutsky said, "When you think about it, in managing ventilator synchrony there are really only 4 parameters you're trying to balance: plateau pressure, $\mathrm{P}_{\mathrm{O}_{2}}, \mathrm{pH}$, and $\mathrm{F}_{\mathrm{IO}_{2}}$. How you weigh those 4 things will determine your optimal ventilator strategy." There were about 15 of us in the room at the time, and he asked us to rank-let's take $\mathrm{F}_{\mathrm{IO}_{2}}$ as the reference-what is "equitoxic" to an $\mathrm{F}_{\mathrm{IO}_{2}}$ of $100 \%$ ? Is a plateau pressure of 25 , $30,35,40,45 \mathrm{~cm} \mathrm{H}_{2} \mathrm{O}$ equitoxic? What $\mathrm{P}_{\mathrm{O}_{2}}$ is equitoxic: $55,60,70 \mathrm{~mm} \mathrm{Hg}$ ? And so on. He submitted this to the people around the room, and the results were all over the chart. There was absolutely no consistency or consensus. Everybody's got in their brain a weighing system for those 4 parameters, and the ranking system depends on the relative weights in your value system. I applaud you for coming up with an interesting schema, but it's going to be very difficult to implement.

Chatburn: Keep in mind that the ranking system describes what ventilators do, not how they are used. It's like saying I have a hammer, a screwdriver, and a saw, and now you have to tell me how you want to use them according to the most important goal at the moment. We are starting to see artificial intelligence used to balance the parameters you mentioned, such as in SmartCare, but that particular system uses only one tool: pressure support. Systems that make expert decisions with more tools, such as Hamilton's Intellivent, are starting to generate patient data.

Arnal et al reported at this year's ATS [American Thoracic Society] meeting that, compared to Adaptive Support Ventilation, patients ventilated with Intellivent spent more time in optimal and suboptimal ventilation and less time in nonsecure ventilation. In addition, Intellivent delivered lower volumes and pressures for equivalent gas-exchange results, suggesting more efficient ventilation. ${ }^{1}$ Also at that meeting, Lellouche, et al reported that Intellivent seemed safer than conventional ventilation after cardiac surgery. ${ }^{2}$

1. Arnal JM, Wysocki M, Demory D, Durish G, Laubscher T, Novotni D, et al. Prospective randomized crossover controlled study comparing Adaptive Support Ventilation (ASV) and a fully close loop control solution (Intellivent) in adult ICU patients with acute respiratory failure (abstract). Am J Respir Crit Care Med 2010;181(Suppl): A3004.

2. Lellouche F, Bouchard PA, Wysocki M, Laubscher T, Novotni D, Lopez R, et al. Prospective randomized controlled study comparing conventional ventilation versus a fully closed-loop ventilation (Intellivent) in post cardiac surgery ICU patients (abstract). Am J Respir Crit Care Med 2010;181(Suppl): A6035.
Younes:* I may appear to be promoting my own PAV [proportional assist ventilation], but if you look at the systems that emphasize safety, they cannot provide synchrony with the patient. But the systems that provide synchrony, such as NAVA [neurally adjusted ventilatory assist] and PAV can be made to be safe by adding backup features and so on, and they can be made to provide liberation by having algorithms that adjust, whereas the other ones cannot do that. So it seems to me that the rational thing to do is to take the ones that can do what the others cannot do and build up the other features that would give them the safety and the ability to liberate the patient.

Chatburn: Thank you. That was exactly what I was hoping someone would say. You take the best features on that grid and see which ones we can combine to make the next generation of better modes. I think that's how things should evolve; they shouldn't evolve haphazardly just because someone thinks they can sell a ventilator. They should evolve with at least some crude sense of evolution as to what's better and what's not. I think that's an excellent way to look at things.

Pierson: $\dagger$ So you're not advising us to manage our patients on multiple different ventilators concurrently?

Chatburn: On the contrary, I would argue for standardization. Pick one and learn how to use it to the best of your ability.

Kacmarek: He is recommending to get rid of the [Puritan Bennett] MA1s.

Branson: Rob, you and I have spent more time than anybody talking about

\footnotetext{
* Magdy Younes MD FRCP(C) PhD, Department of Medicine, University of Manitoba, Winnipeg, Manitoba, Canada.
} 
terminology and I've had this discussion with you before. The term "adaptive" is explanatory or descriptive, whereas "intelligent" or "optimum" are, I think, value statements. I understand where you got the words from, but I think you're in danger of appearing to promote or provide a value based on the name, and I wonder if there is not another way to describe those techniques with descriptive words that don't suggest inherent value. Most of us, when we say "intelligent" we generally think that's good, right?

Chatburn: You can argue that both ways, Rich. I didn't make up those words: they're used in artificial intelligence and engineering, and in the bigger world those words don't have the emotional connotation that you're talking about. Should we bring ourselves down to arbitrary, "non-emotional" words or should we bring ourselves up to contemporary standards of terminology? Should we go out and rename things that have already been established in chemistry and biology and pharmacology just because we don't like those words? I would argue no. Why do that? We already have too much gobbledygook, so let's stick with something that at least has some context, some larger system of science behind it. I'm not in favor of inventing new words to keep some people emotionally comfortable.

Branson: I'm not uncomfortable with it. I just think the word "intelligent" may be perceived by some readers to be better than "adaptive."

Chatburn: I recently did this lecture in another country. Before I gave it, my sponsors asked me to take out the ranking section because they were afraid the culture there would take something like that literally, as you suggest. So you're right that in certain contexts you have to take into consideration how people will interpret the words. I was hoping mostly, believe it or not, to speak to the engineers. Be- cause if the engineers can describe to us what they're doing in a systematic and rational fashion, and put that in the operating manuals, then the rest of us don't have to struggle so hard to understand what their products do. In the printed version of this talk I will make very clear what the words intelligent and adaptive mean, along with their engineering context. I trust that readers will be sophisticated enough to grasp their proper meanings.

Gentile: When you showed us all those modes on the screen, it made me think that we have been taking them apart. We test them on the bench or somewhere else, and we have our own ranking. With SmartCare it's endtidal $\mathrm{CO}_{2}$ monitoring that we don't do anywhere else: we have this adapter inline. We've already proven that the more times you break the ventilator circuit the higher the risk of ventilator-associated pneumonia. Neil [MacIntyre] and I did a bench study on ASV [adaptive support ventilation] and found that when these resistance/ compliance problems surface, the tidal volumes can increase dramatically. And that may be applicable for many other modes. These new modes come along and, until they're proven, we are all very skeptical. I think we're all a little long in the tooth, and we also have to decide on an endpoint: ventilator-liberation, safety, or some similar measure.

Branson: Rob, so ASV, which I think works perfectly fine-and, again, if you told me tomorrow that I had to use ASV on all patients, I think I could successfully accomplish thatbut ASV has been around since 1994. Why isn't it more widely accepted and used? I feel the same way about a lot of these things: if they're so much better, wouldn't we have all figured it out by now?

Chatburn: You might be right about that. The other piece is that, as we've talked about before, even the most ba- sic advances in medicine take a long time to be accepted into practice, even when the evidence is staring us right in the face. There's an emotional component regarding resistance to change, and then there's the intellectual component of "where's the evidence?"

Gentile: I think the answer is that it's all proprietary. We have model A, model $\mathrm{B}$, and model $\mathrm{C}$, and they all have different features on them. We can't do PAV on a Servo-i, and we can't do NAVA on a Puritan Bennett, so I think that's going to be something we'll have to live with.

Chatburn: First of all, Mike, I was just in China, and I can assure you they use the same kinds of ventilators we do and with just as rich an assortment in a single department. In fact, their range is wider than ours. I actually saw a modern Japanese high-frequency ventilator sitting right next to an original Emerson iron lung, both being commonly used with patients.

Rich, I think part of the adoption thing of course comes down to budget, but it's not only, "Do I have the money to buy the latest thing?" It's "Do I have the will to buy the latest thing?" With a large purchase (half a million to a million dollars, say), people tend to buy products they're familiar with. It's human nature. It has nothing to do with the intrinsic value of the technology.

Branson: I would still submit that if 15 years ago a revolutionary technique had been introduced that made patients get better, it would have been evident by now. It just goes back to the fact that, depending on whether your patient needs to be oxygenated or ventilated because of respiratory acidosis or supported because of respiratory muscle fatigue, the mode I would choose would be different in every patient. I think therein lies the problem of why one thing doesn't get adopted. 
Parthasarathy: Even with proprietary modes there are instances where different companies have been coming together. In sleep-disordered breathing, Respironics and ResMed got together to fund a multicenter trial. It's unfortunate that the CANPAP [Canadian Continuous Positive Airway Pressure for Patients with Central Sleep Apnea and Heart Failure] trial $^{1}$ was negative, but I think the investigators learned from that, and they're moving on with the ADVENT-HF [Multi-Centre, Randomized Study to Assess the Effects of Adaptive Servo Ventilation on Survival and Frequency of Cardiovascular Hospital Admissions in Patients with Heart Failure and Sleep Apnea, http://www.controlled-trials.com/isrctn/ pf/67500535] trial now.

These kinds of discussions are great, because when these get published the field should move in that direction, and I think one of the impediments is funding in critical care research. What we're talking about here is a very inhomogenous population, and what works for one group may not work for another, or may be harmful to another. It can only answered by a network, and that's the kind of agenda that a society such as the AARC [American Association for Respiratory Care] or the ATS [American Thoracic Society] should push for.

The biggest criticism I got from the reviewers of a [recent] grant application was that critical illness is a very complex condition with multiple variables and that sleep is also a very complex condition with multiple variables, and you're trying to do research on both of them. The concern is that critical care does not have a review group of its own in the NIH [National Institutes of Health]. Mine went to a panel of psychologists, who looked at my application kindly.

I think the situation is such that there should be something done at a different level to actually propel critical care research forward, to make it so that even individual proprietary companies can come together so that we can get these questions answered. Otherwise, in 25 years will we still be sitting in this same room talking about the same issues, just with a more complex classification system?

\section{Bradley TD, Logan AG, Kimoff RJ, Sériès} F, Morrison D, Ferguson K, et al; CanPAP Investigators. Continuous positive airway pressure for central sleep apnea and heart failure N Engl J Med 2005;353(19):20252033.

Kallet: When you showed that slide on optimizing WOB [work of breathing], it made me think. WOB has been my focus all these years, and you get into this frame of mind, almost subconsciously, of "you gotta minimize it, you gotta minimize it!" But it occurred to me recently, would we have survived as a species if we weren't able to at least double our WOB for extended periods of time? Granted, critical illness is a special context, but I think it illustrates how our assumptions might influence the design of sophisticated ventilator modes in a way that might not be beneficial. Where do you factor that in? As closed-loop ventilation becomes more complex, could our preoccupation with tightly controlling some targets lead us down the wrong path?

Rich Branson and I have talked over the years about how rigidly to control plateau pressure in trauma patients with decreased chest-wall compliance. Do you need to keep the plateau at $30 \mathrm{~cm} \mathrm{H}_{2} \mathrm{O}$ all the time? When do you loosen that up? Same goes for PEEP/ $\mathrm{F}_{\mathrm{IO}_{2}}$ titration. I think when we discuss making a perfect mode, there's so much context to consider that it can also befuddle the design, particularly if we rigidly adhere to rules such as keep the plateau pressure at $30 \mathrm{~cm} \mathrm{H}{ }_{2} \mathrm{O}$, WOB [lt] $0.5 \mathrm{~J} / \mathrm{L}, \mathrm{F}_{\mathrm{IO}_{2}}$ below 0.7 , or whatever. I don't know where we go with that.

Branson: It reminds me of normalizing other things in critical care. What happens when we normalize the he- matocrit? Patients don't do better, they do worse. Think of all the things that we make normal and maybe it's not intelligent to normalize the WOB to what it is in a patient with normal compliance and resistance, I just don't know.

Epstein: We need to know whether these things really cause a bad outcome or if instead they're just markers. If they're markers, then a lot of what we're talking about in terms of changing the way we ventilate patients may not be relevant. We need to know whether this is cause or effect.

Branson: I have to believe, being someone who's been scuba diving, that if you try to take a breath and you don't get any air, it's a frightening, distressing situation.

Epstein: But we're not talking about not getting any air, we're talking about maybe only getting $85 \%$ of the air you might want. What is the threshold where it makes a clinical difference? I don't think we know.

Branson: But I think a missed trigger is more like that. With a missed trigger they get a little bit of gas out of the circuit, but for the most part are not rewarded with a breath. It seems that has to be distressing and uncomfortable and lead to asynchrony. I think that, but I don't know.

Epstein: I agree with the discomfort part. I'm looking at the different kinds of outcomes in terms of the duration of mechanical ventilation, and survival. Some data show it's uncomfortable.

Kacmarek: There is a difference between asynchrony and WOB. The patient can be synchronous with the ventilator and we can still titrate the level of work or effort they do. WOB and synchrony should not be used synonymously. At this conference we're talking about the ventilator not working in conjunction with the patient's desiresnot necessarily saying we should un- 
load the patient completely. We have a whole spectrum of levels of unloading of the patient, but what we desire is that the ventilator and the patient work in synchrony as much as possible, regardless of what level of work we consider for that given patient.

Branson: I guess what I'm saying is that if your mode targets a work, then you are making that a goal.

Epstein: You're making the goal that you want to set the work at X level, but it's not a specific level: it can be at any level you choose. It can be a different level in different patients or in a given patient, depending on the patient's progress.

Branson: I think I agree with you, Bob, but I'm saying that if you choose a mode that has a goal of maintaining WOB at $\mathrm{X}$, then no matter what the patient does, it tries to maintain WOB at X. All I'm saying is, how do we know that level $\mathrm{X}$ is good or bad?

Epstein: We don't.

Branson: And we see patients with COPD get extubated with a WOB of $1.0 \mathrm{~J} / \mathrm{L}$ who do fine.

Epstein: Sure: once you get the endotracheal tube out the work changes pretty dramatically.
Younes: I want to emphasize that bad interactions happen only when we are not awake. When we are awake, we do not allow poor interactions: we try to enforce the good interactions. If we fail to do that, we get panicky and use sedation, and I think the link between this topic and outcome has to do with sedation. If you're using a mode that becomes asynchronous when you're asleep, then it would automatically lead to sedation when you're awake, because the patient would not tolerate it. We all know that excessive sedation contributes to bad outcomes, and I think we may need to look at what is associated with the most sedation and the least sedation.

Parthasarathy: We've observed that too. On these patients, electroencephalography more likely than not shows that the non-triggering events occur during sleep, because they won't allow it when they're awake. We had a hypothesis that non-triggering is associated with the disruption from sleep, but we couldn't find it, because when the patients were non-triggering, they were usually asleep. There were very few non-triggering breaths when they were awake. It seems that if they really need to get that breath, they will find the effort to get that breath. They won't be in the circumstance where they're trying to breathe and they don't get a breath while they're awake.
Pierson: It's like I've been at a debate among the mechanical ventilation gods on respiratory care's Mount Olympus, and it has been a heady experience. This conference has several goals, but I hope one thing that will come out of it is something that can spill down the slopes of the mountain to the readership in terms of practical advice on what we can do about patient-ventilator interaction, right now, with the ventilators we have. I'm hoping we don't come away with the conclusion that you have to have a particular brand or kind of machine to really do mechanical ventilation right.

And I'm also hoping that one doesn't have to have clinicians of the expertise that we have in this room to take good care of patients on ventilators. I think we might all agree that mechanical ventilation as practiced on an everyday basis falls short in terms of both knowledge of the current evidence and the practical application of that evidence: even with what we know for sure, we know that it doesn't get used. In addition to this splendid discussion of the issues we're dealing with, some of them admittedly more theoretical than practical, I hope we will also come out with as much as we can in terms of practical guidance on what to do about these things. 